\title{
Principios de sostenibilidad en clusters de turismo rural: los casos del Alto y el Bajo Danubio en Serbia'
}

\author{
Radmila Jovanović², † Darío César Sánchez ${ }^{3}$, Sanja Pavlović ${ }^{4}$ \\ y Mirjana Devedžićs
}

\begin{abstract}
RESUMEN
El objetivo de la presente investigación es poner en evidencia las dificultades que conlleva el tan declamado desarrollo turístico rural sostenible. Para ello se han elegido dos clusters de turismo rural correspondientes al Alto y el Bajo Danubio, en un país de Europa Oriental de desarrollo medio como es Serbia. La comparación es uno de los principios esenciales de la investigación geográfica y en este caso permitió establecer diferencias y semejanzas entre un destino de naturaleza, con fuertes carencias de infraestructura pero con creciente presencia de turismo internacional, y un destino con mejores servicios y con predominio de atractivos histórico - culturales, más orientado al turismo local. El exhaustivo relevamiento bibliográfico y de campo se complementó con un profundo análisis geo-estadístico de información que año a año recogen los municipios. Los resultados obtenidos aportan conocimientos con vistas a una planificación estratégica en el camino de la sostenibilidad.
\end{abstract}

Palabras clave: principios del turismo sostenible, espacio rural, Alto y Bajo Danubio, Serbia.

\begin{abstract}
The objective of this investigation is to put in evidence the difficulties what it entails the so declaimed sustainable rural tourism development. For that aim, we have chosen two tourism clusters of rural areas corresponding to the Upper and Lower Danube, in a country in Eastern Europe of medium development like as Serbia. The comparison is one of the essential principles of geographical research and in this case are allowed establish differences and similarities between a nature destination with strong deficiencies of infrastructure. On the other side, it is evident an increasing presence of international tourism and destination with better services and predominance of historical and cultural attractions, more oriented to local tourism. The exhaustive bibliographical and field research are complemented by a deep geostatistical analysis of information which are collected from year to year by municipalities. The results obtained are brought knowledge with views to a strategic planning on the path of sustainability.
\end{abstract}

Keywords: sustainable tourism principles, rural area, Upper and Lower Danube, Serbia.

Artículo recibido el 13 de mayo de 2017, aceptado el 19 de agosto de 2017 y corregido el 28 de diciembre de 2017. Facultad de Geografía, Universidad de Belgrado (Serbia). E-mail: jogurada@yahoo.com CONICET - IMHICIHU - GRUTUS (Argentina). E-mail: dariosanchez@conicet.gov.ar Facultad de Geografía, Universidad de Belgrado (Serbia).E-mail: spavlovic20@gmail.com Facultad de Geografía, Universidad de Belgrado (Serbia).E-mail: mdevedzic@gmail.com 
El turismo rural se considera a menudo una de las formas sostenibles del turismo, ya que al atraer a un número reducido de turistas no requiere grandes inversiones en materia de infraestructura y, por ende, no provoca un gran impacto en el destino. La demanda turística se centra, entonces, en la cultura local, que debe ser preservada (Rátz \& Puczkó, 1998; Soyeun \& Tazim, 2015; Idziak et al., 2015; Lane \& Kastenholz, 2015). El mayor problema se presenta en general en la sostenibilidad económica, ya que teniendo en cuenta la estacionalidad de la demanda, la baja tasa de utilización de la capacidad instalada y la necesidad de una considerable inversión inicial, la rentabilidad económica de los pequeños emprendimientos turísticos se presenta como una meta difícil de alcanzar. A favor se presenta el hecho que, en la mayoría de los casos, el turismo no es la principal fuente de ingresos de los hogares rurales, aunque sí una de sus alternativas.

Algunos autores consideran que el desarrollo del turismo puede afectar de manera negativa las características socio-culturales del destino rural, produciendo cambios en la estructura social, presión sobre la comunidad local, aceleración en el ritmo de vida e introduciendo cierta falta de autenticidad en las tradiciones locales (Stankov, 2007: 252). Otros autores, en cambio, consideran que el turismo rural sostenible es un paradigma que se adapta a las condiciones de cada sitio (Cañizares Ruiz, 2013; Fernández \& García, 2011; Gil \& Hernanz, 2014; Bramwell, 2015; Hernández et al., 2016). Como ha señalado en su momento Payne (1993: 254-255), es evidente que el turismo rural sostenible contribuye a enriquecer las actividades económicas, favorece la organización social de los destinos y ayuda a la concientización respecto a las restricciones ecológicas y la preservación del ambiente, que son en términos generales los tres principios básicos de la sostenibilidad.

A partir de la Cumbre Mundial de las Naciones Unidas celebrada en 1992 en Río de Janeiro (Brasil), surgió la necesidad de reconsiderar los principios del desarrollo sostenible; no alcanzaba con el crecimiento económico, sino que debía incluirse también el desarrollo social, es decir asegurar una adecuada calidad de vida para la comunidad local (Berry \& Ladkin, 1997; Farrell, 1999: 190; Liu, 2003: 469; Farsari, 2000: 6). Surgió entonces la necesidad de definir un conjunto o sistema de indicadores que permitiera comparar y evaluar los cambios ambientales, sociales, políticos, culturales y económicos, lo cual permite llevar adelante estrategias y previsiones de desarrollo (Saarinen, 2006; Flores, 2008; Sánchez, 2009; Romagosa et al., 2011). Saarinen (2006: 1131) explica:

- Existe una tradición basada en los recursos y la necesidad de proteger la naturaleza y la cultura local de los cambios que produce la actividad turística;

- Hay otra tradición basada en el apoyo y la protección del capital económico invertido en el turismo;

- También hay una tradición basada en los valores de la comunidad, que busca un aumento del capital social en el contexto local.

Numerosos autores se han esforzado por definir los principios del turismo sostenible y caracterizar su aplicación (Eber, 1992; Bramwell \& Henry, 1996; Tazim \& Tanas, 2005; Stankov, 2007; Campón-Cerro et al., 2017; Amir et al., 2015). También se han ocupado al respecto distintas organizaciones internacionales (OMT, 1993; OMT, 1997; WTTC, OMC y Consejo de la Tierra, 1996; OMT \& PNUMA, 1998). El desarrollo sostenible abarca tres grandes principios: ecológico o ambiental, socio-cultural y económico. El "principio ecológico" implica que el desarrollo turístico no debe oponerse a los procesos ecológicos ni al desarrollo biológico de la zona; por el contrario, debe contribuir a un uso óptimo de los recursos naturales y a su conservación para beneficio de las 
generaciones futuras. Por su parte, el "principio sociocultural" enfatiza el aumento en la participación de las comunidades locales en la toma de decisiones y en la planificación del desarrollo turístico, el respeto por la autenticidad sociocultural de la comunidad local, la preservación de su patrimonio histórico - cultural y sus valores tradicionales, la comprensión intercultural y una amplia tolerancia en las zonas multiétnicas. Por último, el "principio económico" se sustenta en la inversión para el desarrollo, con el objetivo de crear una base para las generaciones futuras, proporcionando beneficios socioeconómicos para la población local y para los propios inversores en el turismo (OMT, 1993). Para que la viabilidad del desarrollo turístico sostenible a largo plazo resulte garantizada, es necesario que se alcance un adecuado equilibrio entre los tres principios señalados (Štetic \& Šimičević, 2008: 23).

En un estudio sobre el concepto de turismo sostenible (RBSC, 2008), a partir de los tres principios generales antes mencionados: ecológico, socio-cultural y económico, se destacan los siguientes elementos: la planificación a largo plazo, la participación integral de la comunidad en la planificación y la gestión del turismo, la reducción de la degradación del medio ambiente a nivel local y global, el impacto del turismo en la singularidad y en la diversidad del patrimonio cultural, la consideración de los impactos locales y globales, promoviendo el consumo sostenible, equilibrando la sostenibilidad con la calidad socio-ambiental, insistiendo en una participación activa de todos los interesados, incluyendo el seguimiento continuo de los indicadores del turismo rural.

En el presente trabajo se analizan los principios del turismo sostenible en las zonas rurales del Alto y el Bajo Danubio, llevando a cabo su comparación y realizando recomendaciones a los fines de proponer mejoras en la oferta turística. Para lograr el desarrollo sostenible del turismo es indispensable enfocar de forma integral su planificación y gestión. Los resultados de esta investigación pueden indicar a los ofertantes de los productos turísticos las posibilidades y los límites de su progreso, facilitarles tanto el desarrollo de los planes estratégicos como el fomento de los productos turísticos basados en el patrimonio natural y cultural, ayudar a que se planifique con más eficacia la infraestructura y superestructura, así como la promoción de los destinos. En este contexto, el trabajo aporta una contribución más aplicable que teórica, brindando conocimientos útiles y objetivos a funcionarios, autoridades y comunidad local para la toma de decisiones en el camino hacia un desarrollo turístico realmente sostenible.

\section{Métodos de investigación}

En términos generales, la metodología utilizada ha sido preponderantemente exploratoria, tanto cualitativa como cuantitativa. En el primer caso se recurrió al primer paso del método en geografía: la observación directa y el contacto in situ con los atractivos naturales y culturales y con las comunidades locales, la visita de los establecimientos rurales, la interacción con propietarios, empleados, pobladores y turistas, el recorrido de los caminos y las sendas, la percepción sensorial y la vivencia, analizando y evaluando equipamiento e infraestructura en cada uno de los destinos. La profunda experiencia previa en el conocimiento del territorio facilitó la selección de los casos de estudio. Esta tarea se complementó con el aprovechamiento de la información estadística secundaria que concentra el gobierno nacional a través del Anuario Estadístico de Municipios de la Oficina de Estadística de la República de Serbia, que no es mucha, pero un pormenorizado análisis geo-estadístico permitió complementar la percepción con la información cuantitativa. La conjunción metodológica constituye un aporte en sí mismo, ya que no se reco- 
nocen antecedentes de estudios similares al menos en Serbia. Por otra parte, el "principio de comparación", magistralmente aplicado por el alemán Karl Ritter (1817) en su "Geografía general comparada", es uno de los principios geográficos tradicionales (Daus, 1973:29-34). En esta investigación la comparación implicó un estudio simultáneo de las similitudes y diferencias en el desarrollo sostenible de los clústeres turísticos del Alto y el Bajo Danubio, a los efectos de evaluar los factores que dificultan tal desarrollo.

En cuanto a la metodología estadística, toda la información secundaria con que contamos se hallaba concentrada en dos tablas por cada año para el período 2003-2015, es decir en 26 tablas que había que revisar y ordenar. Casi siempre en las tablas hay errores y esta vez también los hubo. En los primeros años había números con espacios, que al hacer operaciones eran tomados como texto o cero. También había un error con valores invertidos en la última fila del año 2005. Cuando no tenemos mucha información, como en este caso, debemos aprovechar al máximo la disponible. Dado que teníamos datos para un período de trece años, decidimos organizar la información en tablas diacrónicas, es decir con información de un mismo indicador para distintos momentos en el tiempo, considerando tres niveles de análisis: los municipios, las dos regiones y la suma de ambas como un todo. Se generaron entonces nueve tablas diacrónicas para definir igual número de indicadores expresados en valores absolutos, para el período 2003 - 2015:

- Turistas Nacionales (TN)

- Turistas Internacionales (TI)

- $\operatorname{Turistas}(\mathrm{T})$

- Pernoctaciones de Turistas Nacionales (PN)

- Pernoctaciones de Turistas Internacionales (PI)

- Pernoctaciones de Turistas (P)

- Inversiones del Sector Turismo (IST)

- Empleados en el Sector Turismo (EST)

- Empleados en el Municipio (EM)

En la última fila se volcó, para cada tabla, el porcentaje correspondiente a Podunavlje Inferior. Estas nueve tablas brindan muchísima información para el análisis, y para facilitar la interpretación se les agregó, para cada unidad espacial, el promedio, la desviación standard, el coeficiente de variabilidad y los valores máximo y mínimo de cada indicador para el período 2003 - 2015. Establecidos los promedios de ambas regiones y sus municipios para los nueve indicadores expresados en valores absolutos, se construyó con ellos una Matriz Síntesis de Indicadores con catorce nuevos indicadores expresados en valores relativos (porcentajes y cocientes) y por lo tanto absolutamente comparables para territorios con pesos demográficos disímiles (Cuadro $N^{\circ} 1$ ):

- Empleados en el Sector Turismo \% (ET\%)

- Inversiones del Sector Turismo / Empleados en el Municipio (I/EM)

- Inversiones del Sector Turismo / Empleados en el Sector Turismo (I/ET)

- Inversiones del Sector Turismo / Turistas (I/T)

- Inversiones del Sector Turismo / Pernoctaciones (I/P)

- Turistas / Empleados en el Municipio (T/EM)

- Turistas / Empleados en el Sector Turismo (T/ET)

- Turistas Internacionales \% (TI\%)

- Pernoctaciones / Empleados en el Municipio (P/EM) 
- Pernoctaciones / Empleados en el Sector Turismo (P/ET)

- Pernoctaciones de Turistas Internacionales \% (PI\%)

- Duración de la Estadía Media de los Turistas (DE)

- Duración de la Estadía Media de los Turistas Nacionales (DEN)

- Duración de la Estadía Media de los Turistas Internacionales (DEI)

Cuadro $N^{\circ} 1$

Matriz Síntesis de Indicadores - Promedios 2003 - 2015

\begin{tabular}{|l|r|r|r|r|r|r|r|r|r|r|r|r|r|r|}
\hline Municipio & ET\% & I/EM & I/ET & I/T & I/P & T/EM & T/ET & TI\% & P/EM & P/ET & PI\% & DE & DEN & DEI \\
\hline Apatin & 1,01 & 243 & 34359 & 146 & 24 & 1,71 & 241 & 18,8 & 9,9 & 1345 & 11,5 & 6,10 & 6,66 & 3,71 \\
\hline Bač & 0,98 & 119 & 24685 & 1330 & 243 & 0,03 & 3 & 14,4 & 0,1 & 13 & 20,1 & 4,82 & 5,19 & 2,74 \\
\hline Bačka Palanka & 0,82 & 334 & 54687 & 1313 & 584 & 0,26 & 42 & 48,8 & 0,6 & 93 & 53,3 & 2,20 & 1,99 & 2,44 \\
\hline Odžaci & 0,65 & 100 & 47958 & 11654 & 6335 & 0,01 & 5 & 31,9 & 0,0 & 15 & 32,0 & 2,45 & 2,39 & 2,30 \\
\hline Sombor & 1,18 & 110 & 14585 & 216 & 100 & 0,54 & 61 & 26,5 & 1,2 & 136 & 28,2 & 2,14 & 2,10 & 2,21 \\
\hline Veliko Gradište & 2,74 & 114 & 5263 & 18 & 8 & 7,42 & 354 & 5,9 & 16,4 & 752 & 5,1 & 2,37 & 2,39 & 1,83 \\
\hline Golubac & 3,68 & 47 & 1693 & 9 & 6 & 5,79 & 190 & 11,4 & 8,9 & 293 & 10,0 & 1,53 & 1,56 & 1,39 \\
\hline Kladovo & 2,37 & 348 & 19183 & 59 & 23 & 6,37 & 297 & 8,9 & 15,9 & 750 & 9,2 & 2,48 & 2,47 & 2,59 \\
\hline Majdanpek & 2,86 & 132 & 6500 & 21 & 10 & 6,44 & 250 & 11,3 & 13,4 & 526 & 11,3 & 2,10 & 2,10 & 2,14 \\
\hline Negotin & 1,35 & 138 & 47056 & 188 & 80 & 0,83 & 143 & 10,2 & 1,8 & 336 & 8,1 & 2,21 & 2,28 & 1,77 \\
\hline Promedio & 1,76 & 169 & 25597 & 1495 & 741 & 2,94 & 159 & 18,8 & 6,8 & 426 & 18,9 & 2,84 & 2,91 & 2,31 \\
\hline Desv. Standard & 1,00 & 98 & 18429 & 3421 & 1872 & 2,97 & 120 & 12,6 & 6,5 & 403 & 14,3 & 1,36 & 1,56 & 0,60 \\
\hline Coef. & & & & & & & & & & & & & & \\
Variabilidad & 56,7 & 58,0 & 72,0 & 228,8 & 252,6 & 101,0 & 75,9 & 67,3 & 94,8 & 94,6 & 75,6 & 48,0 & 53,6 & 26,1 \\
\hline
\end{tabular}

Fuente: Elaboración propia.

El Cuadro $\mathrm{N}^{\circ} 1$ es una Matriz Síntesis de Indicadores porque sus valores $\mathrm{x}_{\mathrm{ij}}$, representan los promedios de los catorce nuevos indicadores $\left(X_{j}\right)$ para el período $2003-2015$, correspondiendo las filas (i) a los municipios y las columnas (j) a los indicadores. Se procedió entonces a obtener el promedio $\left(\mu_{\mathrm{j}}\right)$ y la desviación standard $\left(\sigma_{\mathrm{j}}\right)$ de cada indicador $(\mathrm{j})$, y a continuación la estandarización de toda la matriz mediante:

$\mathrm{z}_{\mathrm{ij}}=\left(\mathrm{x}_{\mathrm{ij}}-\mu_{\mathrm{j}}\right) / \sigma_{\mathrm{j}}(1)$

Sabiendo que los indicadores estandarizados $\left(Z_{j}\right)$ cumplen con las propiedades:

$\mu_{\mathrm{z}}=0(2)$

$\sigma_{z}=1(3)$

se eligieron cuatro límites de clases $\left(\lambda_{\mathrm{k}}\right)$ a intervalos constantes $\sigma_{z}=1$

$\lambda_{1}=\mu_{z}+1,5 \sigma_{z}=1,5(4)$

$\lambda_{2}=\mu_{z}+0,5 \sigma_{z}=0,5(5)$

$\lambda_{3}=\mu_{z}-0,5 \sigma_{z}=-0,5(6)$

$\lambda_{4}=\mu_{z}-0,5 \sigma_{z}=-1,5(7)$ 
los cuales permitieron determinar, para cada indicador, cinco clases areales cuya interpretación se presenta en el Cuadro $\mathrm{N}^{\circ} 2$.

Cuadro $\mathrm{N}^{\circ} 2$

Clasificación Univariada con Parámetros Estadísticos $\mu$ y $\sigma$

\begin{tabular}{|l|c|}
\hline Fundamentación Analítica (Límites) & Interpretación (Valores) \\
\hline$x_{i}>\mu+1 \frac{1}{2} \sigma$ & Muy altos \\
\hline$\mu+1 \frac{1}{2} \sigma \geq x_{i}>\mu+1 / 2 \sigma$ & Altos \\
\hline$\mu+1 / 2 \sigma \geq x_{i}>\mu-1 / 2 \sigma$ & Medios \\
\hline$\mu-1 / 2 \sigma \geq x_{i}>\mu-11 / 2 \sigma$ & Bajos \\
\hline$\mu-1 \frac{1}{2} \sigma \geq x_{i}$ & Muy bajos \\
\hline
\end{tabular}

Fuente: Elaboración propia.

Definida la Matriz de Indicadores Estandarizados $\left(Z_{j}\right)$ y a continuación su matriz transpuesta, se obtuvo la Matriz de Correlaciones Lineales $\left(R_{14 \times 14}\right)$ (Cuadro $N^{\circ} 3$ ).

Cuadro $\mathrm{N}^{\circ} 3$

Matriz de Correlaciones (R)

\begin{tabular}{|l|r|r|r|r|r|r|r|r|r|r|r|r|r|r|}
\hline & ET\% & \multicolumn{1}{|c|}{ I/EM } & I/ET & \multicolumn{1}{l|}{ I/T } & \multicolumn{1}{l|}{ I/P } & T/EM & T/ET & \multicolumn{1}{c|}{ TI\% } & P/EM & P/ET & PI\% & \multicolumn{1}{c|}{ DE } & \multicolumn{1}{l|}{ DEN } & \multicolumn{1}{c|}{ DEI } \\
\hline ET\% & 1,00 & $-0,27$ & $-0,82$ & $-0,45$ & $-0,42$ & 0,91 & 0,70 & $-0,64$ & 0,74 & 0,24 & $-0,62$ & $-0,46$ & $-0,43$ & $-0,57$ \\
\hline I/EM & $-0,27$ & 1,00 & 0,42 & $-0,19$ & $-0,19$ & $-0,03$ & 0,15 & 0,34 & 0,17 & 0,34 & 0,31 & 0,20 & 0,17 & 0,54 \\
\hline I/ET & $-0,82$ & 0,42 & 1,00 & 0,47 & 0,46 & $-0,76$ & $-0,57$ & 0,66 & $-0,65$ & $-0,22$ & 0,61 & 0,20 & 0,17 & 0,34 \\
\hline I/T & $-0,45$ & $-0,19$ & 0,47 & 1,00 & 1,00 & $-0,42$ & $-0,52$ & 0,43 & $-0,44$ & $-0,41$ & 0,41 & $-0,05$ & $-0,08$ & 0,03 \\
\hline I/P & $-0,42$ & $-0,19$ & 0,46 & 1,00 & 1,00 & $-0,38$ & $-0,48$ & 0,42 & $-0,40$ & $-0,38$ & 0,39 & $-0,09$ & $-0,12$ & 0,01 \\
\hline T/EM & 0,91 & $-0,03$ & $-0,76$ & $-0,42$ & $-0,38$ & 1,00 & 0,88 & $-0,65$ & 0,93 & 0,47 & $-0,64$ & $-0,34$ & $-0,31$ & $-0,35$ \\
\hline T/ET & 0,70 & 0,15 & $-0,57$ & $-0,52$ & $-0,48$ & 0,88 & 1,00 & $-0,67$ & 0,96 & 0,79 & $-0,73$ & $-0,05$ & $-0,03$ & $-0,07$ \\
\hline TI\% & $-0,64$ & 0,34 & 0,66 & 0,43 & 0,42 & $-0,65$ & $-0,67$ & 1,00 & $-0,64$ & $-0,44$ & 0,98 & $-0,05$ & $-0,09$ & 0,22 \\
\hline P/EM & 0,74 & 0,17 & $-0,65$ & $-0,44$ & $-0,40$ & 0,93 & 0,96 & $-0,64$ & 1,00 & 0,73 & $-0,67$ & $-0,05$ & $-0,04$ & $-0,03$ \\
\hline P/ET & 0,24 & 0,34 & $-0,22$ & $-0,41$ & $-0,38$ & 0,47 & 0,79 & $-0,44$ & 0,73 & 1,00 & $-0,58$ & 0,48 & 0,49 & 0,49 \\
\hline PI\% & $-0,62$ & 0,31 & 0,61 & 0,41 & 0,39 & $-0,64$ & $-0,73$ & 0,98 & $-0,67$ & $-0,58$ & 1,00 & $-0,11$ & $-0,16$ & 0,15 \\
\hline DE & $-0,46$ & 0,20 & 0,20 & $-0,05$ & $-0,09$ & $-0,34$ & $-0,05$ & $-0,05$ & $-0,05$ & 0,48 & $-0,11$ & 1,00 & 1,00 & 0,87 \\
\hline DEN & $-0,43$ & 0,17 & 0,17 & $-0,08$ & $-0,12$ & $-0,31$ & $-0,03$ & $-0,09$ & $-0,04$ & 0,49 & $-0,16$ & 1,00 & 1,00 & 0,85 \\
\hline DEI & $-0,57$ & 0,54 & 0,34 & 0,03 & 0,01 & $-0,35$ & $-0,07$ & 0,22 & $-0,03$ & 0,49 & 0,15 & 0,87 & 0,85 & 1,00 \\
\hline
\end{tabular}

Fuente: Elaboración propia.

Se realizó a continuación un Linkage Analysis utilizando el método de Mc Quitty, que se basa en graficar en un diagrama las correlaciones máximas de cada uno de los indicadores, sin considerar su nivel de significación. Cuando la correlación máxima del indicador A es con B y la de B es 
con A se define un par recíproco, que constituye el núcleo o corazón de un factor, obteniéndose tantos factores como pares recíprocos; en nuestro caso resultaron cuatro. En síntesis, la metodología estadística utilizada permitió optimizar el aprovechamiento de la escasa información disponible, con tratamientos sincrónicos y diacrónicos, de valores absolutos y relativos, y con análisis univariados, bivariados y multivariados.

\section{Principios de sostenibilidad del turismo rural en la región del Danubio}

En Serbia se investiga a la región del Danubio como un espacio multidisciplinar, integrándola a veces al resto de la cuenca como una porción de un territorio mayor. Existen numerosos proyectos, documentos estratégicos y fondos de recursos para su investigación; uno de ellos es el Programa Conjunto de Turismo Sostenible para el Desarrollo Rural, financiado por el Fondo Español para el logro de los Objetivos de Desarrollo del Milenio, el cual se tradujo en el Plan Maestro para el Desarrollo Sostenible del Turismo Rural en Serbia. Entre los doce clusters de turismo rural establecidos por el Plan Maestro se encuentran el Alto y el Bajo Danubio, pero este último es uno de los tres prioritarios. En cuanto a sus mayores ventajas y menores riesgos, el Bajo Danubio fue clasificado en quinto lugar y el Alto Danubio en octavo (OMT, 2011: 87-89). El Bajo Danubio está bien posicionado para el desarrollo del turismo ligado al patrimonio histórico-cultural, mientras que el Alto Danubio presenta mayores perspectivas en relación con la naturaleza, los deportes y actividades como la caza, la pesca, la observación de aves, etc. (OMT, 2011: 94-95) (Figura N 1).

Una de las prioridades del desarrollo sostenible en Serbia es el desarrollo rural (Gaceta Oficial, 2007: 13). Diferentes zonas rurales, gracias a su patrimonio natural y artificial, así como a las características ecológicas y ambientales de su territorio, representan un recurso potencial para el desarrollo del turismo sostenible. Teniendo en cuenta que este turismo depende de la fisonomía geográfica de las zonas rurales, éstas son las auténticas ventajas comparativas para el desarrollo de este tipo de turismo en Serbia (Premović et al., 2011: 160).

La diversificación de la economía rural de una manera social, económica y ambientalmente sostenible, resulta necesaria para mejorar la calidad de vida de la población, reducir su nivel de pobreza y luchar contra la degradación social y ecológica (Radović et al., 2013: 427). El concepto de turismo rural sostenible implica en Serbia diferentes niveles de organización (nacional, regional y local) y la participación simultánea e integrada del sector público, las entidades empresariales, las instituciones educativas, las asociaciones de agricultores, las ONG, las instituciones financieras, las organizaciones de turismo locales, los medios de comunicación, los proveedores de servicios turísticos, los residentes e inclusive los propios turistas (Radović et al., 2013: 430).

La Estrategia de la Unión Europea para la región del Danubio y el Plan de Acción adoptado para su desarrollo por los catorce países del Danubio participantes, incluido Serbia, están basados en cuatro temas principales (EU, 2010):

- la conexión y comunicación, el transporte, la infraestructura de apoyo y la energía;

- la protección del medio ambiente, la prevención de riesgos y el uso sostenible de los recursos naturales; 
Figura $\mathrm{N}^{\circ} 1$

Localización de las regiones del Alto y Bajo Danubio

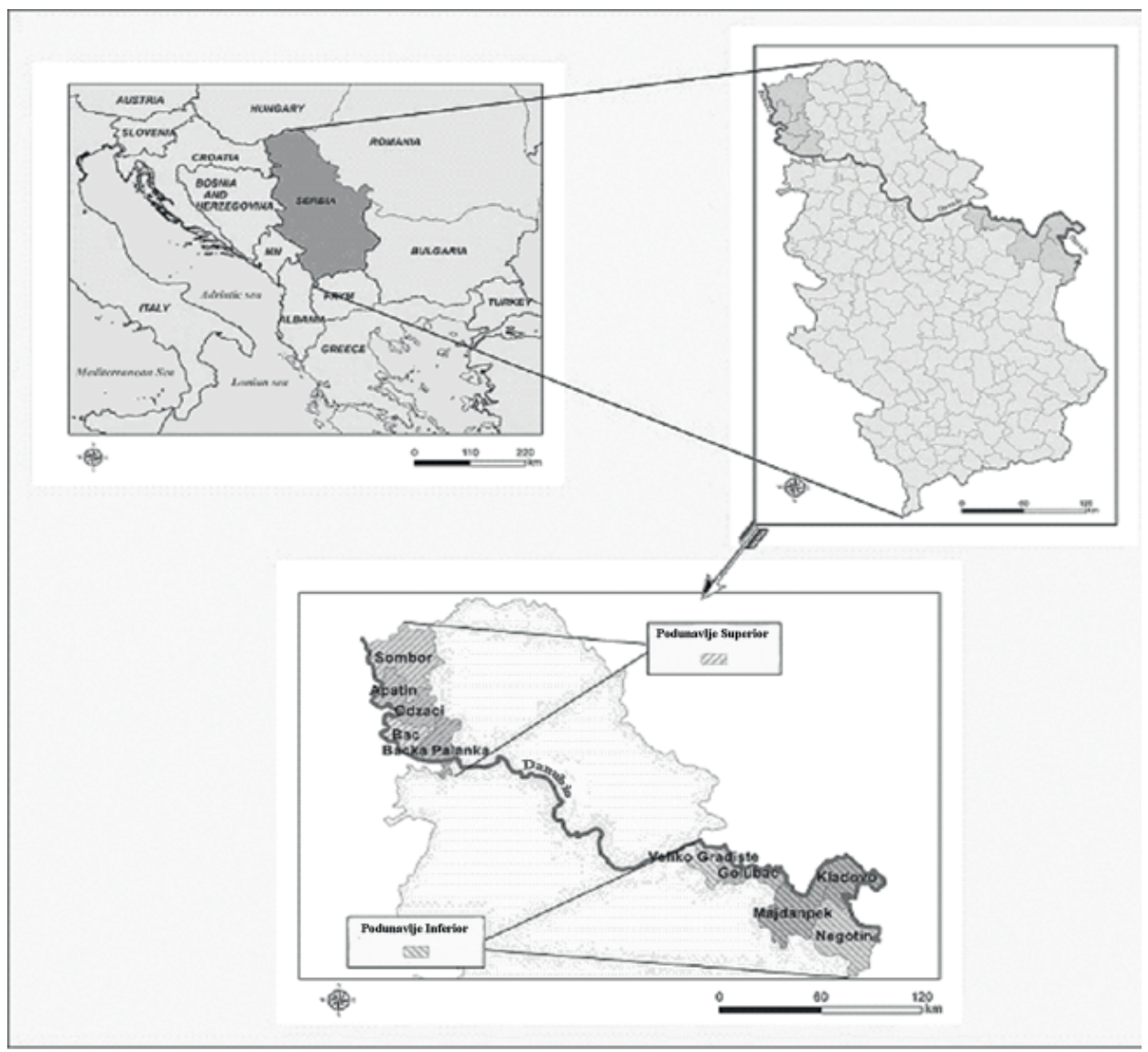

Fuente: Elaboración propia.

- el desarrollo socio-económico e institucional;

- el fortalecimiento de la cooperación regional.

La protección del medio ambiente, el uso sostenible de los recursos naturales y el desarrollo socio-económico están directamente relacionados con los principios del desarrollo sostenible del turismo y los proyectos que se ejecutarán se aplicarán en gran medida en las zonas rurales.

\section{Principios ecológicos de turismo sostenible}

El más importante recurso turístico natural del cluster de turismo rural del Bajo Danubio se encuentra en el Parque Nacional Djerdap, a lo largo del río Danubio, que ocupa una superficie de 63.608,45 hectáreas y representa el mayor parque nacional de Serbia, un área protegida con atractivos geomorfológicos, hidrológicos y biogeográficos (Lovreta et al., 2007a: 3). En este parque nacional se presta gran atención a la organización y protección de los recursos hídricos y la 
zona ribereña, de acuerdo con los principios del desarrollo sostenible y la planificación urbana y territorial, con buen marketing y señalización (Lovreta et al., 2007a: 4). El Parque Nacional Djerdap limita con el Parque Nacional Portile de Fier de Rumania, lo que permite la cooperación transfronteriza. Además de los recursos naturales que se encuentran bajo protección en la zona (18 en total, entre ellos 9 reservas naturales y un parque natural regional), existen otros importantes recursos para el desarrollo del turismo, como el Lago Djerdap y Puerta de Hierro, de $100 \mathrm{~km}$ de largo (Štetić et al., 2014: 114-115).

Los principales atractivos naturales del destino turístico Alto Danubio son la Reserva Natural Especial del Alto Danubio, con su biodiversidad, y el propio río Danubio. La reserva cubre un área de 19.618 hectáreas de bosques, praderas, lagunas y pantanos, incluyendo el río Danubio y sus meandros. Se extiende a lo largo de la orilla izquierda del Danubio y representa una de las últimas grandes áreas ecológicas ribereñas del continente europeo (Lovreta et al., 2007b: 4). Esta reserva natural especial pertenece a la IPA por su variedad botánica, a la IBA por su diversidad de aves, a la PBA por sus mariposas, constituye un sitio Ramsar y a la vez es parte de la Red Esmeralda. La protección se lleva a cabo a través del régimen de tres niveles, afectando el nivel de protección I al 1,5\% de la reserva, el nivel de protección II al 25\% de la reserva y el nivel de protección III al 73,5\% restante del territorio total. La zona de protección de interfaz con el usuario permite actividades como el senderismo y paseos en bote; en la zona Il se pueden realizar trabajos de investigación y excursiones con guía, con la posibilidad de realizar un campamento controlado. Por último, la zona de protección III posibilita un turismo sostenible en el que se permiten servicios de alojamiento, instalaciones turísticas, centros de información turística para visitantes, etc. La Reserva Natural Especial del Alto Danubio limita con el Parque Natural Kopacki Rit de Croacia y el Parque Nacional del Danubio - Drava de Hungría, conformando una cooperación transfronteriza entre los tres países con sus recursos naturales protegidos (Štetić et al., 2014: 121). Es la primer área protegida de Serbia y ha sido nominada para el turismo sostenible en la Carta Europea de las Areas Protegidas a principios de 2014, en un proyecto de Arco Parques Dináricos del Fondo Mundial para la Naturaleza (WWF).

El principal objetivo de la certificación del turismo sostenible es aumentar la calidad de los servicios y la protección de la naturaleza, gestionar los recursos de manera que se puedan cubrir las necesidades económicas, sociales y estéticas de los turistas y conservar la identidad cultural y la diversidad biológica, con la colaboración y cooperación de todos los usuarios (OMT, 1997). A fines de 2014, la reserva del Alto Danubio recibió la Carta Europea de Turismo Sostenible de la Federación Europarc, la organización más importante para las áreas protegidas del continente. En el futuro se espera que la UNESCO la declare Reserva de Biosfera del río transfronterizo Mura - Drava - Danubio.

La protección internacional por lo general atrae a más turistas y esto contribuye a una mejor organización de los destinos y una más adecuada utilización de los recursos turísticos (Stojanović et al., 2014: 1-2). No obstante, la Reserva Especial de Naturaleza Alto Danubio es parte del Cinturón Verde Europeo, una iniciativa paneuropea que abarca 22 países. Los objetivos de la creación de una red ecológica a lo largo de la ruta de la antigua Cortina de Hierro, son: vincular la conservación de la biodiversidad y el desarrollo rural sostenible, integrar a las comunidades locales y proteger la naturaleza a través de la cooperación transfronteriza (Stojanović et al., 2014: 5). 
El potencial del ecoturismo en la región del Alto Danubio proporciona oportunidades para idear rutas educativas y ecológicas temáticas, que permitan a los niños y jóvenes aprender acerca de la naturaleza y su protección. Se han construido tres caminos educativos circulares equipados con paneles informativos, lugares para relajarse, torres de vigilancia, etc. Cada año, estos caminos son recorridos por apenas unos 500 turistas, lo cual está muy por debajo del potencial de oportunidades del turismo. Los visitantes son estudiantes, alumnos y amantes de la naturaleza, y la mayoría de ellos realiza actividades de aprendizaje acerca de los ecosistemas y hábitats locales, estudios sobre la vegetación, observación de aves y animales en general, participando en los campamentos de voluntarios (Stojanović et al., 2014:14-15).

\section{Los principios socio-culturales del turismo sostenible}

En la región del Danubio, los productos turísticos son resultado de la vinculación de los diferentes grupos étnicos con el turismo, activando y reactivando las antiguas costumbres y las respectivas artesanías, preservando así la identidad cultural y aumentando en consecuencia el atractivo general de la zona analizada. En la cultura y las civilizaciones del Bajo Danubio se conservan rasgos de tiempos muy antiguos, los cuales se corresponden con restos de la cultura de la Temprana Edad de Piedra, 8000 años antes de Cristo, así como con otros más recientes de la época romana. El Bajo Danubio es un espacio en el que se mezclan los atractivos naturales con la cultura, la historia y las tradiciones de las personas que vivieron y las que viven en la actualidad. Se han desarrollado emprendimientos turísticos en las cercanías de Negotin y aldeas en el Parque Nacional Djerdap, las cuales por el momento mantienen un bajo nivel de desarrollo en cuanto a la comercialización del turismo rural como producto (Lovreta et al., 2007a: 5).

El Plan Maestro del destino turístico Alto Danubio incluye una cartera de productos entre los que se destaca el turismo rural en las granjas de las zonas de Sombor y Apatin (Lovreta et al., 2007b: 13). Algunas granjas conservan el atraso y a la vez la autenticidad, mientras que otras fueron reconstruidas con unos pocos elementos auténticos. La función económica se fusiona hoy con la cultura, la arquitectura tradicional, la producción agrícola y las instalaciones necesarias para el mercado turístico (Štetić et al., 2014: 142-143). Uno de los principales distintivos demográficos y culturales de la región es la diversidad étnica, ya que en esta zona hay cerca de 20 grupos étnicos, siendo los más numerosos los serbios, los húngaros, los croatas y los eslovacos. Esta heterogeneidad étnica es consecuencia de la colonización implementada en los últimos siglos, y se asocia a una rica tradición, importante ingrediente para un turismo rural sostenible.

Los objetivos del proyecto IPA, realizado en el marco de la cooperación transfronteriza con Croacia, son el desarrollo social y cultural y la gestión sostenible de los recursos naturales y culturales a través del desarrollo del turismo rural (Stojanović et al., 2014: 7). La dinámica demográfica, el envejecimiento de la población y su estructura étnica son elementos muy importantes para una adecuada interpretación de la realidad socio-cultural y las posibilidades de sostenibilidad del turismo rural. El crecimiento de Serbia durante el período democrático se caracteriza por un desarrollo regional desigual, alta centralización y concentración y paralelo despoblamiento de algunos territorios. Las regiones fronterizas, incluyendo el Alto y el Bajo Danubio, son ejemplos típicos de este último proceso. Por lo tanto, el potencial demográfico se reduce y también es evidente la tendencia hacia un mayor debilitamiento económico. 
La subregión del Alto Danubio cuenta con el asentamiento más grande entre los clusters de turismo rural, y en tal sentido no se muestra demográficamente tan débil como el Bajo Danubio, pero en ambas áreas se observa un progresivo despoblamiento y un proceso de envejecimiento de la población. En las zonas rurales del Bajo Danubio la edad promedio de la población es de más de 45 años; en todos los asentamientos los mayores de 65 años superan en número a los menores de 15 años de edad. En algunos pueblos que se perciben como portadores de oferta turística, se ha producido una pérdida continua de población, siendo hoy apenas un $20 \%$ de la existente finalizada la Segunda Guerra Mundial, con una edad media actual de 58 años de edad.

El aumento de la población en algunas comunidades rurales del Bajo Danubio durante el último período intercensal debe ser correctamente interpretado; muy probablemente se debe a que muchas viviendas construidas como residencias de fin de semana, particularmente en zonas suburbanas y muy próximas a las carreteras, con el tiempo pasaron a transformarse en residencias permanentes, tal es el caso del asentamiento Kostol. Dado que el despoblamiento continuo reduce el potencial reproductivo y la inmigración se presenta como una utopía, es difícil hablar de la revitalización de estos asentamientos. Las mayores posibilidades de revitalización parcial se dan en los asentamientos con una población de mayor tamaño, en los que todavía vive una cantidad significativa de población joven. Esa población en la franja de edad de 20 a 39 años representa los recursos demográficos que pueden sostener el desarrollo del turismo, lo que a su vez podría ser un incentivo para evitar la emigración y el estancamiento económico.

Los asentamientos de la región del Alto Danubio se caracterizan por su heterogeneidad étnica, con presencia de serbios, croatas y húngaros, lo que refleja el importante intercambio fronterizo entre los respectivos países. Esta diversidad favorece a la industria turística, propiciando la organización de eventos que involucran la cooperación transfronteriza y entre las distintas colectividades. En cambio, los asentamientos del Bajo Danubio presentan mucho menor grado de heterogeneidad étnica. Solo en dos pueblos con población significativa de nacionalidad rumana, sus tradiciones específicas y su creatividad contribuyen a la riqueza cultural de la zona. Otros asentamientos son casi étnicamente homogéneos, con más del $90 \%$ de serbios según el censo de población de 2011 (Censo Nacional de Población, 2011).

\section{Principios Económicos de Sostenibilidad Turística}

En el marco del Programa Conjunto de las Naciones Unidas sobre Turismo Sostenible para el Desarrollo Rural, financiado por el Reino de España a través del fondo para el logro de los Objetivos de Desarrollo del Milenio (ODM), se apoyan iniciativas plasmadas en proyectos que tienen como objetivo la diversificación de las economías locales. Este Programa asigna recursos a tres iniciativas locales que han ofrecido soluciones innovadoras, aplicables y sostenibles, para la producción de artesanías y actividades en respuesta a las necesidades de los mercados turísticos locales y regionales. Una de estas iniciativas es estimular los antiguos oficios relacionados con la producción de objetos cerámicos. El programa distribuyó $32.000 €$ entre los asentamientos de Kladovo, Majdanpek, Požarevac y Veliko Gradište, en el Bajo Danubio, para alentar la producción de objetos de cerámica que en parte se venden a los turistas y en parte son absorbidos por los propios hogares que ofrecen los servicios turísticos (Rollinger, 2012: 52). 
Una segunda iniciativa que puede contribuir con el turismo rural, con un presupuesto de $21.000 €$, es la que se realiza en el marco del Programa Eco de Plata en el municipio de Veliko Gradište. Este programa turístico - ambiental conjuga el fomento del turismo con fines de pesca deportiva con la educación ambiental. El turista, además de pescar, puede visitar la cooperativa de artesanos, aprender sus métodos tradicionales, iniciarse en la fabricación de artículos de cerámica e inclusive recorrer la reserva de Ade Čibuklija, reconocida internacionalmente por su gran variedad de especies de aves (Rollinger, 2012: 54). En tercer lugar, el Programa Guardemos Nuestro Tesoro, con un presupuesto de $22.500 €$, busca mejorar la infraestructura para el turismo rural en la localidad de Kladovo. El mayor problema detectado en este asentamiento fue la deficiente infraestructura para la eliminación de los residuos sólidos, motivo por el cual se colocaron contenedores de distinto color para la separación de los mismos (Rollinger, 2012: 56).

Asimismo, en el marco del apoyo del PNUD / FMAM para el financiamiento sostenible de las áreas protegidas de Serbia, en 2013 se aprobó un proyecto para la creación y promoción de un sistema de carreteras para el turismo ecológico y sostenible en el Parque Nacional Djerdap, por un monto de $27.783 €$. Entre los objetivos de este proyecto se destacan desarrollar y promover el uso sostenible de los recursos naturales y culturales, fortalecer las comunidades locales, difundir la nueva marca y recurrir a tecnologías de última generación (Rollinger, 2012). En 2013 se inició también la ejecución del proyecto del Bajo Danubio "El más bello rostro del turismo", en el marco del Plan de Subvenciones para el Desarrollo Socio-económico de la Región del Danubio en Serbia. El presupuesto del proyecto, financiado con fondos de la Unión Europea, la Agencia Austriaca para el Desarrollo (ADA) y una pequeña porción de recursos nacionales, alcanza los $224.825 €$. Este proyecto prevé, entre otras cosas, la parquización de algunas áreas con la incorporación de caminos peatonales y bicisendas, la generación de infraestructura y accesos para la práctica del canotaje y el piragüismo y la formación de guías turísticos en los municipios de Negotin y Kladovo.

Merece señalarse que actualmente las tendencias en el turismo europeo hacen hincapié en la salud, la naturaleza, la ecología y el desarrollo sostenible, pero la región del Alto Danubio presenta grandes potencialidades para el turismo aventura, el cual requiere por lo general de una infraestructura compleja y específica, y sin embargo no se han producido en esta región inversiones significativas al respecto. Las principales inversiones financieras han sido producto de iniciativas privadas. Se cuenta con señalización turística y caminos educativos, pero falta un centro para los visitantes con un sector gastronómico y venta de distintos productos y servicios. La gestion adecuada de este espacio podría brindar nuevas posibilidades de trabajo, así como otras vías de comercialización para productos agrícolas locales tales como miel, queso y cereales. Desde los gobiernos locales se deberia estimular el interés por las inversiones en turismo, con el fin de concatenar las organizaciones nacionales con las internacionales (Stojanović et al., 2014).

\section{Análisis geo-estadístico}

Un condicionamiento típico para el análisis geográfico es la forma en que la información estadística se encuentra desagregada. En este caso en particular, los datos estadísticos se presentan a nivel municipal, no por asentamientos, y esto limita el nivel de detalle de las interpretaciones y conclusiones. Por otra parte, solo se cuenta con información para los años 2003 a 2015. Al considerar el componente inflacionario, se advierte que la inversión en el Sector Turismo (IST) a valores constantes habría tendido a disminuir a lo largo del periodo investigado. Por otra parte, se observa una participación creciente de la región del Bajo Danubio en las inversiones turísticas, 
pasando del 13,8\% en 2003 a 30,4\% en 2015. En la región del Alto Danubio la mayor beneficiaria ha sido Backa Palanka, mientras que en la región del Bajo Danubio viene siendo Kladovo, con un importante crecimiento relativo.

La relación entre la inversión y el empleo (I/EM) es un indicador de la importancia relativa de tales inversiones. En este caso permite ver cómo las mayores inversiones abandonan la subregión Superior y se instalan en la Inferior, particularmente en Kladovo. Al relacionar la inversión exclusivamente con el empleo turístico (I/ET) se confirma lo anterior y se observa también la importante inversión recibida por Backa Palanka en el Alto Danubio y Negotin en el Bajo Danubio. No obstante, en relación con el número de turistas $(\mathrm{I} / \mathrm{T})$ se observa en cambio que la inversión es muy modesta, e inclusive casi ínfima en el Bajo Danubio, aunque con tendencia a un mayor equilibrio. La consideración de las pernoctaciones (I/P) arroja idénticos resultados (Instituto de Estadística de la República, 2003-2015) (Figura N²).

Figura $\mathrm{N}^{\circ} 2$

Inversión en turismo - Valores estandarizados

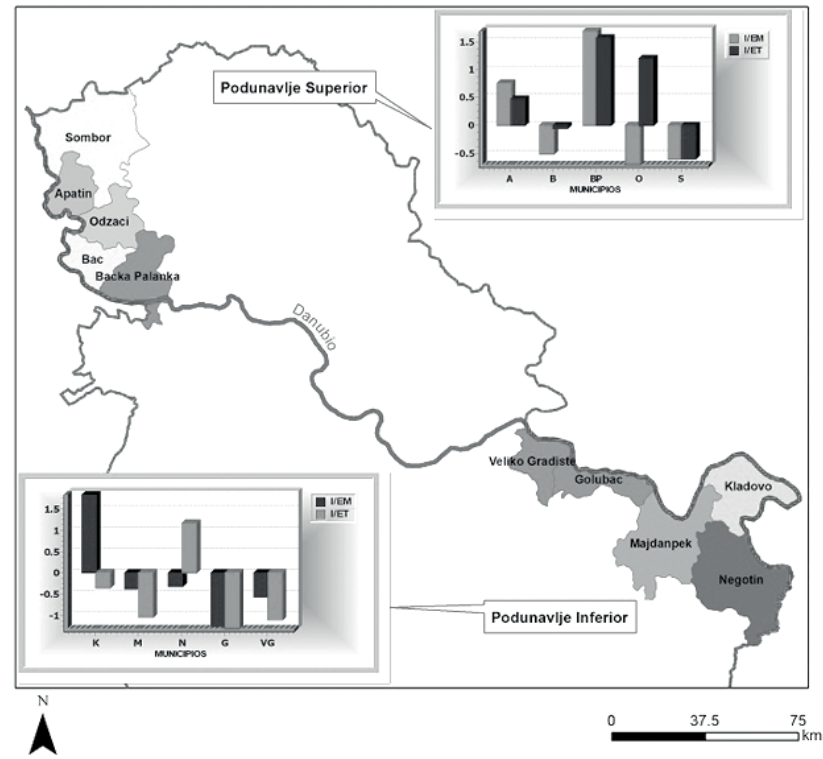

Fuente: Elaboración propia.

El número de empleados en el municipio (EM) es un indicador de la actividad económica. Se observa un importante crecimiento del empleo en los últimos dos años considerados, que involucra por igual a las dos regiones y a todos los municipios. En 2012 los empleados del Sector Turismo (EST) representaban apenas un 38,9\% en relación con los que había en 2003, pero en 2015 hubo un muy significativo repunte, observándose en los últimos años un mayor incremento en la región del Alto Danubio, sobre todo en Sombor, que cuenta con casi la mitad de los empleados en turismo de la región. Al considerar la participación relativa del sector turismo en el empleo (ET\%), se observa que pese al reciente incremento todavía es muy modesta (3,56\%), alcanzando sus valores máximos en la región del Bajo Danubio, en Golubac (8,45\%) y Veliko Gradiste $(7,15 \%)$. 
Dentro de este panorama, salvo Majdanpek todos los municipios han visto incrementado su porcentaje de empleo turístico en el período 2002 - 2015 (Anuario Estadístico de Municipios de Serbia, 2003-2015).

El empleo en general viene creciendo en los últimos dos años, y este es un dato muy alentador, pero el empleo turístico es bajo en términos absolutos y también relativos, las inversiones siguen siendo muy modestas y el número de turistas y sus pernoctaciones se hallan estancados. La relación Turistas / Empleados (T/EM) muestra la mayor importancia relativa del turismo en la región del Bajo Danubio, donde se aprecia un cierto perfil turístico en municipios como Veliko Gradiste, Majdanpek, Kladovo y Golubac. También muestra la escasa importancia de la actividad en el Alto Danubio, donde apenas aparece con cierta trascendencia Apatin. No obstante, se observa en general una tendencia al crecimiento, resultado de un significativo incremento en el Bajo Danubio y un estancamiento en el Alto. Esto estaría indicando que, al menos en la región Inferior el turismo podría ser una alternativa para el desarrollo. La consideración específica de los empleados en el Sector Turismo (T/ET) confirma lo previamente expresado (Figura $N^{\circ} 3$ ).

Figura $\mathrm{N}^{\circ} 3$

Relación turistas / empleados - Valores estandarizados

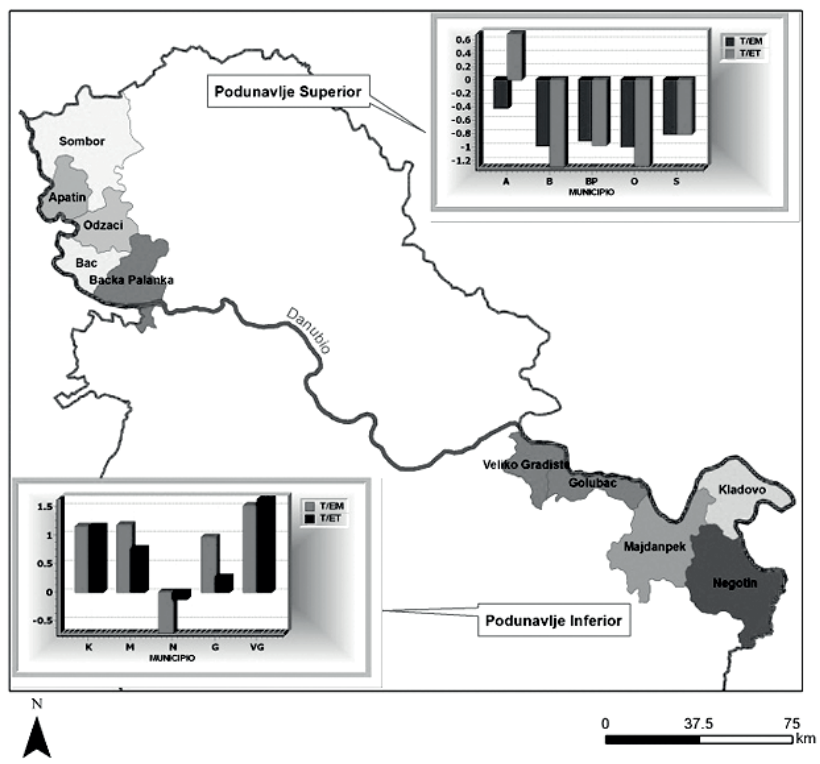

Fuente: Elaboración propia.

El número de turistas $(T)$ muestra en el área de estudio una situación de estancamiento en torno a los cien mil visitantes, con un pico máximo en 2008 con 113.722 turistas. Durante todo el período investigado la región Inferior concentró siempre entre el $73 \%$ y el $83 \%$ del total de turistas, destacándose Majdanpek, Kladovo y Veliko Gradiste en ese orden. Al considerar el origen de los turistas, se comprueba que los turistas nacionales (TN) van lentamente decreciendo, habiendo alcanzado su pico máximo en 2007 con poco más de cien mil visitantes. Se concentran mayorita- 
riamente en la región del Bajo Danubio, representando un 81,5\% del total, pero el decrecimiento en el período se ha dado en ambas regiones.

El indicador más alentador es el referido al turismo internacional ( $\mathrm{TI})$, que mostró una tendencia creciente a lo largo de todo el período y en ambas regiones, aunque con mayor fuerza en el Bajo Danubio, que concentró el 62,9\% del total en 2015, donde los principales destinos elegidos por los extranjeros fueron Majdanpek (4631) y Kladovo (3556). En el Alto Danubio merece mencionarse a Sombor con 3268 turistas extranjeros para dicho año. La participación de los turistas internacionales ( $\mathrm{TI} \%$ ) en el territorio creció de manera constante durante todo el período, pasando de 4,7\% en 2003 a 21,7\% en 2015. En términos absolutos se pasó de 4000 a 18500 turistas extranjeros en doce años. En cuanto a la presencia relativa de turistas extranjeros respecto al total de turistas, el porcentaje es sensiblemente mayor en el Alto Danubio (32,7\%) que en el Bajo Danubio $(18,1 \%)$, destacándose Backa Palanka (58,6\%) como el único municipio entre los investigados que recibió mayor numero de turistas extranjeros que nacionales, seguramente muchos de ellos provenientes de la vecina Croacia, en virtud del puente internacional que la une con la localidad de Ilok (Figura $\mathrm{N}^{\circ} 4$ ).

La duración media de la estadía (DE) no muestra cambios significativos en su evolución temporal. Para el territorio en su conjunto es de aproximadamente dos días y medio $(2,54)$, siendo significativamente mayor en el Alto Danubio $(3,72)$ que en el Bajo $(2,18)$. En tal sentido, merece destacarse la estadía media en Apatin $(6,10)$, que supera los seis días. Al considerar la estadía media de los turistas nacionales (DEN), dado que representan un alto porcentaje del total no se observan diferencias significativas, alcanzándose valores promedio de 2,57 días, con 2,23 para el Bajo Danubio y 4,07 para el Alto y destacándose una vez más el caso de Apatin $(6,66)$. Por su parte, los turistas internacionales (DEI) muestran una reducción en sus estadías pasando de 2,63 días en 2003 a 2,36 días en 2015. Del mismo modo su estadía promedio es levemente inferior $(2,41)$, tanto en la región del Alto Danubio $(2,70)$ como en la del Bajo Danubio $(2,16)$. Nuevamente se destaca el mayor promedio en Apatin $(3,71)$.

Se observan tendencias similares cuando se analiza de número de pernoctaciones $(\mathrm{P})$, que muestra una situación de estancamiento, con valores en torno a 250.000 y un pico máximo en 2008 de 281.544 pernoctaciones. A lo largo del período se comprueba una pérdida de pernoctaciones en el Bajo Danubio, con valores más o menos constantes en el Alto Danubio. En 2015 el Bajo Danubio concentraba el $64,3 \%$ de las pernoctaciones, destacándose Kladovo, Majdanpek y Veliko Gradiste en ese orden, y Apatin en la región Superior. Al considerar el origen de los turistas, se comprueba que las pernoctaciones de los serbios (PN) fueron lentamente decreciendo a lo largo de la década analizada, habiendo alcanzado su pico máximo en 2008 con un total de 252.044. Dos tercios de las mismas se concentran en la región del Bajo Danubio, pero ambas regiones vienen perdiendo lentamente pernoctaciones de serbios a lo largo de todo el período considerado.

En contraposición, las pernoctaciones internacionales (PI) muestran una tendencia creciente a lo largo de todo el período y en todo el territorio bajo estudio, aunque con mayor fuerza en la región del Bajo Danubio (57,6\% en 2015), donde los principales destinos elegidos por los extranjeros son Majdanpek y Kladovo. Por su parte, en la región Superior se destacan como destinos internacionales Sombor y Apatin. En síntesis, mientras decrecen las pernoctaciones nacionales aumentan las internacionales, de manera que la participación relativa de las pernoctaciones internacionales (PI\%) ha crecido de manera constante, pasando de 4,8\% en 2003 a 20,0\% en 2015. La 
Figura $\mathrm{N}^{\circ} 4$

Turismo internacional - Valores estandarizados

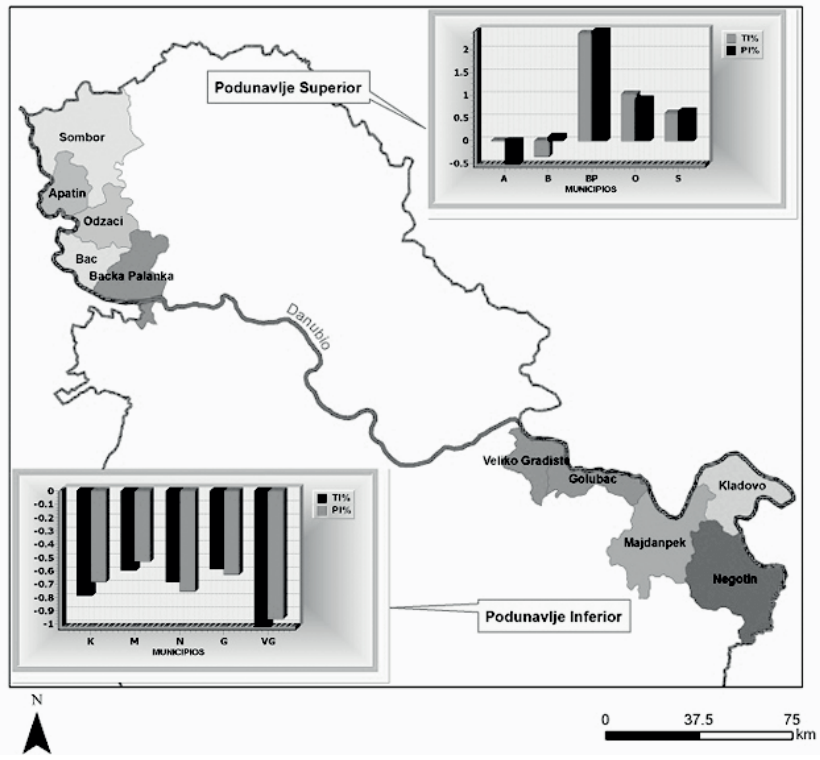

Fuente: Elaboración propia.

mayor presencia relativa de pernoctaciones de extranjeros se da en la región Superior, sobre todo en Bac (70,9\% en 2015), Backa Palanka (63,7\%) y Sombor (41,4\%), destacándose Golubac $(29,0 \%$ en 2015) y Majdanpek (23,6\%) en el Bajo Danubio.

La relación Pernoctaciones / Empleados en el Municipio (P/EM) muestra a través del tiempo que la actividad turística no se ha desarrollado significativamente y desempeña un papel marginal y aún decreciente en la economia del territorio considerado. En el Bajo Danubio se observa cierto perfil turístico en municipios como Veliko Gradiste, Kladovo y Majdanpekvo, mientras que en la región Superior apenas se destaca Apatin, pero en todos los casos no terminan de consolidarse como destinos turísticos emergentes. La consideración específica de los empleados en el Sector Turismo (P/ET) en lugar de los empleados en general, no hace más que confirmar lo previamente expresado.

A modo de síntesis, mediante un Linkage Analysis utilizando el método de Mc Quitty se intentó identificar los principales factores intervinientes en la problemática abordada, los cuales condicionan la sostenibilidad de la actividad turistica. Resultaron cuatro factores:

- Inversión Turística: a todas luces resulta insuficiente y crece a un ritmo inferior a la inflación. Existen fuertes carencias en material de infraestructura y equipamiento que limitan las posibilidades de un desarrollo sostenible. Históricamente el Danubio Superior recibió mayor inversion, en particular los municipios de Backa Palanka y Sombor, mientras que en el Danubio Inferior solo merece mencionarse Kladovo. 
- Empleo en el Sector Turismo: informal y estacional en la mayoría de los establecimientos, con bruscas variaciones a través del tiempo. No hay mayores diferencias entre ambas regiones, destacándose Sombor en el Danubio Superior y Majdanpek en el Inferior.

- Estadía media: ronda los dos días y medio y no se ha podido incrementar por falta de una planificación estratégica que permita la puesta en valor de nuevos atractivos complementarios a los existentes. Predomina el turismo de fín de semana con la sóla excepción de Apatin, en la region Superior, que cuenta con tres hoteles y un "spa" en Junakovic y es famosa por sus iglesias y estatuas, así como por sus posibilidades de pesca y cabalgata en el bosque.

- Turismo internacional: es el indicador que más alienta la esperanza de consolidar un desarrollo turístico sostenible, ya que viene creciendo de manera sostenida, sobre todo en la region Inferior, donde se destacan Majdanpek y Kladovo. En la region Superior el mayor número de visitantes extranjeros se da en Sombor. El turismo internacional proviene en su gran mayoría de los países limítrofes, donde deberían realizarse campañas de promoción.

Figura $\mathrm{N}^{\circ} 5$

Relación entre inversión y turistas internacionales

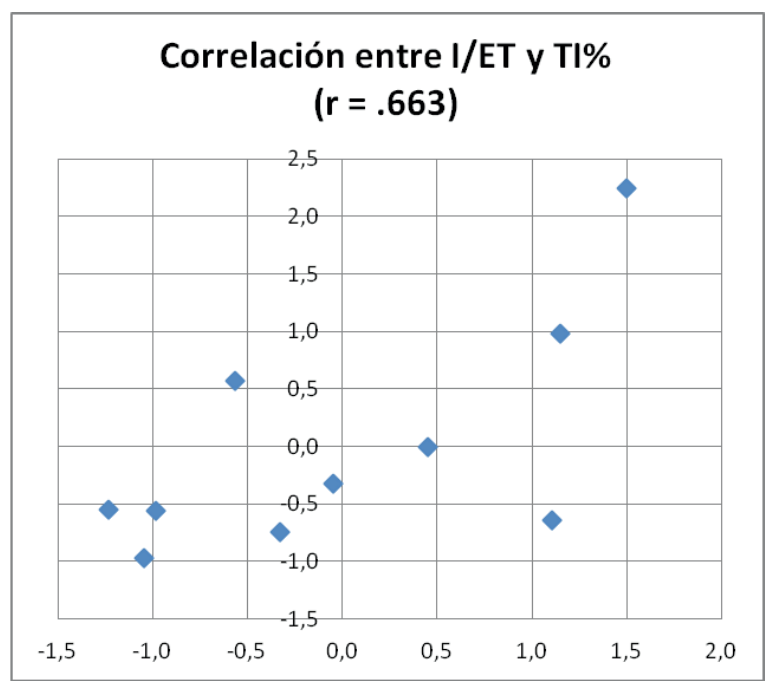

Fuente: Elaboración propia.

Las cuarenta tablas elaboradas brindan abundante información que permite todo tipo de análisis, excediendo las posibilidades de la presente publicación. En particular, la matriz de correlaciones $\mathrm{R}$ nos muestra muy interesantes relaciones entre los indicadores, destacándose la estrecha asociación entre la inversion en turismo y el arribo de turistas internacionales. El diagrama de dispersión de la Figura $N^{\circ} 5$ muestra una relación directa que refleja claramente que a mayor inversión en términos relativos mayor es la presencia porcentual de turistas extranjeros. Aplicando el test $t$ de Student se comprueba que la correlación $(r=.663)$ es significativa con un nivel de confianza del $95,0 \%$. Los valores estandarizados correspondientes a ambos indicadores permiten 
observar que la región del Alto Danubio presenta mayores niveles de inversión relativa (en relación con el empleo) y mayores porcentajes de participación de turistas extranjeros que el Bajo Danubio. Esto se comprueba al advertir que la mayoría de los municipios de la región Superior aparecen en el primer cuadrante del diagrama, mientras que los de la región del Bajo Danubio se presentan mayoritariamente en el tercer cuadrante.

\section{Conclusiones y recomendaciones}

Para que el desarrollo del turismo esté en consonancia con los principios del desarrollo sostenible, debe cumplir con ciertos requisitos, como contribuir a la conservación de la diversidad biológica, asegurar el bienestar de la población local y su educación, favorecer las pequeñas empresas y fomentar la participación local. A la vez, la presencia de diferentes tipos de turismo en el medio rural debe basarse en el hecho de que no actúen de manera aislada, sino que se entrelacen y combinen. Estas combinaciones de modalidades y de servicios deben responder a la demanda de los turistas, por lo que es necesario tener en cuenta sus características. Por ejemplo, el perfil de los visitantes del Alto Danubio, es el de una élite turística de "aventureros" altamente educados que valoran la importancia de los recursos naturales y la preservación del ambiente. Evaluemos ahora el grado de cumplimiento de los principios del turismo rural sostenible en ambas regiones (Cuadro $N^{\circ} 4$ ).

Es evidente que el Alto y el Bajo Danubio son dos áreas geográficamente diferentes, en las que los principios del turismo sostenible se manifiestan de manera distinta. El Alto Danubio obtuvo recientemente una Certificación Europea, lo cual le permitirá al turismo sostenible un mejor posicionamiento en el mercado. Sin embargo, no se advierte hasta el momento en la región la aplicación de los principios económicos de la sostenibilidad, mientras que los principios ecológicos y los socio-culturales parecen cumplirse al menos parcialmente. También faltan las inversiones financieras necesarias para un clúster de turismo rural. En ambos destinos la contribución del turismo rural a la economía local es a priori relativamente baja, por lo menos a juzgar por los ingresos financieros registrados, aunque no existen estadísticas fiables respecto a los ingresos del turismo rural y es difícil diferenciar los impuestos derivados de la actividad turística del resto de los impuestos, de manera que no se pueden establecer con precisión los beneficios económicos del turismo.

Uno de los modelos aplicables se refiere a la administración de la cooperación regional fuera de las fronteras de los clústeres analizados del turismo rural, especialmente si se tiene en cuenta que la cuenca del Alto Danubio y la del Bajo Danubio son espacios limítrofes. La oportunidad potencial para el desarrollo del turismo y los beneficios económicos de la población local consiste en lanzar los productos típicos de determinadas zonas, a lo que deberían dedicarse las organizaciones turísticas, los gobiernos locales y la población.

Como se ha visto, el territorio acusa pérdida de empleo en general, con escasa población ocupada por el turismo, con muy poca inversión en el sector y un número de visitantes y pernoctaciones estancado. El único indicador esperanzador es la presencia creciente de turistas extranjeros. Al analizar por regiones vemos que en el Alto Danubio el turismo es una actividad muy marginal, aunque con mayor presencia de extranjeros, mientras que en el Bajo Danubio va ganando poco 
Cuadro $\mathrm{N}^{\circ} 4$

Principios del turismo rural sostenible en el Alto y el Bajo Danubio

\begin{tabular}{|c|c|c|c|}
\hline Región & Ecológicos & Socioculturales & Económicos \\
\hline $\begin{array}{l}\text { Alto } \\
\text { Danubio }\end{array}$ & $\begin{array}{l}\text { Bosques con biodiversidad } \\
\text { vegetal y animal y recursos } \\
\text { hidrográficos (el río Danu- } \\
\text { bio, canales y afluentes). } \\
\text { Se desarrolla la conciencia } \\
\text { de la población local res- } \\
\text { pecto a la protección de la } \\
\text { naturaleza mediante aso- } \\
\text { ciaciones y talleres ecoló- } \\
\text { gicos, se fomenta el uso de } \\
\text { la bicicleta y los caminos } \\
\text { peatonales y educativos. }\end{array}$ & $\begin{array}{l}\text { Multiculturalismo, arte- } \\
\text { sanías tradicionales, ar- } \\
\text { quitectura con valor his- } \\
\text { tórico - cultural, eventos } \\
\text { y festivales. Presencia de } \\
\text { asociaciones y entidades } \\
\text { ambientales, así como } \\
\text { cooperación internacional } \\
\text { en la zona fronteriza. }\end{array}$ & $\begin{array}{l}\text { Desempleo y en gene- } \\
\text { ral atraso económico } \\
\text { en comparación con los } \\
\text { años ochenta del siglo } \\
\text { pasado, con aplicación } \\
\text { de métodos agrícolas no } \\
\text { sostenibles. Se observa } \\
\text { una modesta inversión en } \\
\text { el turismo, basada sobre } \\
\text { todo en esfuerzos indivi- } \\
\text { duales. }\end{array}$ \\
\hline $\begin{array}{l}\text { Bajo } \\
\text { Danubio }\end{array}$ & $\begin{array}{l}\text { Se destaca el Parque Na- } \\
\text { cional Djerdap, que alber- } \\
\text { ga un bosque de montaña } \\
\text { que podría estar mejor } \\
\text { conservado. Presencia de } \\
\text { senderos para caminantes } \\
\text { y bicisendas; en algunos } \\
\text { asentamientos rurales se } \\
\text { acondicionaron playas en } \\
\text { la ribera del Danubio. }\end{array}$ & $\begin{array}{l}\text { Multiculturalismo, con im- } \\
\text { portante presencia de la } \\
\text { comunidad Vlach, tradi- } \\
\text { ciones de crianza propias } \\
\text { de las mujeres Aktiv, expo- } \\
\text { siciones de trajes típicos } \\
\text { y muebles Vlach. Una Et- } \\
\text { no-Eco Asociación realiza } \\
\text { el Festival de la Creatividad } \\
\text { Popular. }\end{array}$ & $\begin{array}{l}\text { Equipamiento e infraes- } \\
\text { tructura crecientes. Fo- } \\
\text { mento del trabajo en ac- } \\
\text { tividades vinculadas al } \\
\text { turismo. Prestamos del } \\
\text { Ministerio de Agricultura } \\
\text { para la gestión sostenible } \\
\text { del agua. Turismo en ho- } \\
\text { gares rurales. }\end{array}$ \\
\hline
\end{tabular}

Fuente: Elaboración propia.

a poco mayor protagonismo. No obstante, los residentes locales muestran determinación por impulsar el turismo, y en tal sentido deben definir una orientación estratégica basada en el desarrollo sostenible. La población participa activamente en los talleres con vistas a la elaboración de un plan de acción y la creación de asociaciones locales que contribuyan a fortalecer el proyecto. Su actuación es independiente de los factores externos y se recurre a intercambios con instituciones extra-regionales solo para obtener asesoramiento. En este sentido, tanto en el Alto como en el Bajo Danubio, la comunidad local, sobre la base de iniciativas individuales y la creación de asociaciones locales, intenta desarrollar el turismo sin un claro plan de acción ni una participación amplia de expertos que permitan orientar en la toma de decisiones.

Por encima de estos niveles locales, para alcanzar un desarrollo sostenible es necesario establecer sólidos vínculos de integración en una estrategia global de gestión integrada de los recursos naturales. A partir de la redefinición de la normalización internacional de las áreas protegidas, se hace necesario promover la cooperación entre las organizaciones ecologistas y turísticas a nivel nacional, regional y local. A la vez, la cooperación y la coordinación con las organizaciones internacionales debería contribuir a la formación de expertos en la sostenibilidad 
de los recursos naturales para beneficio del turismo rural. En virtud de la situación actual y las tendencias en el mercado turístico, si este tipo de investigación pudiera repetirse dentro de una década es muy probable que los resultados fueran diferentes. Esto dependerá entre otras cosas de necesarios cambios en la legislación y su aplicación en la práctica, los cuales deberán considerar la variada tipología de expresiones turísticas y, por supuesto, la participación protagónica de los gobiernos locales.

\section{Referencias bibliográficas}

AMIR, A.; GHAPAR, A.; JAMAL, S. \& AHMAD, K. Sustainable tourism development: A study on community resilience for rural tourism in Malaysia. Procedia - Social and Behavioral Sciences, 2015, $\mathrm{N}^{\circ}$ 168, p. 116-122.

BERRY, S. \& LADKIN, A. Sustainable tourism: a regional perspective. Tourism Management, 1997, Vol. 18, No 7, p. 433-440.

BRAMWELL, B. \& HENRY, I. A framework for understanding sustainable tourism management. Sustainable Tourism Management: Principles and Practice. Tilburg: Tilburg University Press, 1996.

BRAMWELL, B. Theoretical activity in sustainable tourism research. Annals of Tourism research, 2015, No 54, p. 204-218.

CAMPÓN-CERRO, A.M; HERNÁNDEZ-MOGOLLÓN, J.M. \& ALVES, H. Sustainable improvement of competitiveness in rural tourism destinations: The quest for tourist loyalty in Spain. Journal of Destination Marketing \& Management, 2017, № 6, p. 252-266.

CAÑIZARES RUİZ, M. Sustainability and tourism: from international documentation to planning in Spain Horizon 2020. Boletín de la AGE, 2013, No 61, p. 373-378.

DAUS, F. A. Qué es la geografía. Buenos Aires, Columba, 1973.

EBER, S. Beyond the Green Horizon: a discussion paper on principles for sustainable tourism. London: WWF and Tourism Concern, 1992.

EUROPEAN UNION (EU). Strategija EU za Dunavski region 2010. Disponible en internet: http://www.mfa.gov.rs/sr/ index.php/spoljna-politika/eu/ regionalna-saradnja/eusdr? la ng=lat

FARRELL, B.H. Conventional or sustainable tourism? No room for choice. Tourism Management, 1999, Vol. 20, N², p. 189-91.

FARSARI, Y. Sustainable tourism indicators for Mediterranean established destinations. Heraklion. Nea Alikarnassos: Institute of Applied and Computational Mathematics (IACM), Foundation for the Research and the Technology Hellas (FORTH), 2000. 
FERNÁNDEZ, J.I. \& GARCÍA, P.J. Rural tourism in Spain. Strategies guidelines for a developing tipolog. Boletín de la Asociación de Geógrafos Españoles, 2011, No 56, p. 431-433.

FLORES, J.C. Tourism in the Spanish protected areas, something more than a new trend. Boletín de la Asociación de Geógrafos Españoles, 2008, № 46, p. 407-411.

GIL, F.M. \& HERNANZ. I.M. The Spanish rural areas: territories where tourism is produced and consumed or sustainable tourism destination in a competitive environment? The case of Northeast of Segovia. Boletín de la AGE, 2014, №64, p. 447-453.

HERNÁNDEZ, J.M.; SUÁREZ-VEGA, R. \& SANTANA-JIMÉNEZ, Y. The inter-relationship between rural and mass tourism: The case of Catalonia, Spain. Tourism Management, 2016, $N^{\circ} 54$, p. 43-57.

IDZIAK, W.; MAJEWSKI, J. \& ZMYŚLONY, P. Community participation in sustainable rural tourism experience creation: a long-term appraisal and lessons from a thematic villages project in Poland. Journal of Sustainable Tourism, 2015, Vol. 23, N 8-9, p. 1341-1362.

LANE, B. \& KASTENHOLZ, E. Rural tourism: the evolution of practice and research approaches towards a new generation concept? Journal of Sustainable Tourism, 2015, Vol. 23, N 8-9, p. 11331156.

LIU, Z. Sustainable tourism development: a critique. Journal of Sustainable Tourism, 2003, Vol. 11, No 6, p. 459-475.

LOVRETA, C. Skracena verzija Master plan turisticke destinacije Donje Podunavlje. Beograd: Naucno-istraživacki centar Ekonomski fakultet, 2007a.

LOVRETA, C. Master plan turisticke destinacije Gornje Podunavlje - skracena verzija. Beograd: Naucno-istraživacki centar Ekonomski fakultet, 2007b.

ORGANIZACIÓN MUNDIAL DEL TURISMO (OMT). Sustainable tourism development: Madrid: Guide for local planners, 1993.

ORGANIZACIÓN MUNDIAL DEL TURISMO (OMT). Opšti kodeks etike u turizmu, 1997. Disponible en internet:

http://www.fondacijamisija.org/vesti/frushka-gora-i-gornje-podunavlje-dobijaju-evropski-sertifikat-za-odrzhivi-turizam.

ORGANIZACIÓN MUNDIAL DEL TURISMO (OMT). Master plan odrzivog razvoja ruralnog turizma u Srbiji, 2011. Disponible en internet:

http://future hospitalityleaders.files.wordpress.com/2012/11)

ORGANIZACIÓN MUNDIAL DEL TURISMO (OMT) / PROGRAMA DE LAS NACIONES UNIDAS PARA EL MEDIO AMBIENTE (PNUMA). Charter for Sustainable Tourism, International Conference on Sustainable Tourism in Small Island Developing States (SIDS) and Other Islands, 1998. Disponible en internet: http://www.insula.org/tourism/charte.htm 
RADOVIĆ, G.; PEJANOVIĆ, R. \& KOŠIĆ, K. Koncept organizovanja odrzivog razvoja ruralnog turizma u Republici Srbiji. Anali Ekonomskog fakulteta u Subotici, 2013, Vol. 49, № 29, p. 421-432.

PAYNE, R. Sustainable tourism: Suggested indicators and monitoring techniques. In: NELSON, J.G.; BUTLER, R. \& WALL, G. (coordinador). Tourism and Sustainable Development: Monitoring, Planning, Managing. Waterloo: University of Waterloo, 1993, p. 249-254.

PREMOVIĆ, J.; BOLJEVIĆ, A. \& ARSIĆ, L. J. Turizam u funkciji održivog razvoja Srbije. Agroekonomika, 2011, N 51-52, p. 155-164.

PROJEKAT DONJE PODUNAVLJE - LEPŠE LICE TURIZMA, 2013. Disponible en internet: http://www. npdjerdap.org/donje-podunavlje-lep\%C5\%A1e-lice-turizma/, 10.08.2014.

PROJEKAT PODRŠKA KREIRANJU I PROMOCIJI PUTEVA RAZVOJA ZA EKO I ODRŽIVI TURIZAM U NP ĐERDAP. 2013. Disponible en internet: http://www.npdjerdap.org

ROLAND BERGER STRATEGY CONSULTANTS (RBSC). Koncept održivog turizma u RH - prvi koraci poduzeti, nedostaje holistički pogled. Zagreb: Roland Berger Strategy Consultants, 2008.

REPUBLIČKI ZAVOD ZA STATISTIKU. Statistički godišnjak Opštine u Srbiji. [Zvanični podaci], 20032015.

REPUBLIČKI ZAVOD ZA STATISTIKU. Popis stanovništva 2011. [Zvanični podaci], 2012.

RÁTZ, T. \& PUCZKÓ, L. Rural Tourism and Sustainable Development in Hungary. In: HALL, D. \& O'HANLON, L. (editors). Rural Tourism Management: Sustainable Options, International Conference, Conference Proceedings. Ayr: SAC, Auchincruive, 1998, p.450-464.

ROLLINGER, L. Izgradnja lokalnih kapaciteta za ruralni razvoj usmerena na unapređenje turizma. Beograd: Program Ujedinjenih nacija za razvoj (UNDP) u okviru Zajedničkog programa Ujedinjenih nacija Održivi turizam u funkciji ruralnog razvoja., 2012.

ROMAGOSA, F.; PRIESTLEY, G. \& LLURDÉS, J.C. Tourism in the context of a general sustainable development strategy in Catalonia. Boletín de la Asociación de Geógrafos Españoles, 2011, Nㅜ 57, p. $474-454$.

SAARINEN, J. Tradition of Sustainability in Tourism Studie. Annals of Tourism Research, 2006, Vol. $33, N^{\circ} 4$, p. 1121-1140.

SÁNCHEZ, D.C. (director). Sistema básico de indicadores de sustentabilidad turística de la República Argentina. Propuesta metodológica. Buenos Aires: Secretaría de Turismo de la Nación; CONICET, 2009.

SLUŽBENI GLASNIK, R. S. Nacionalna strategija odrzivog razvoja, 2007, br. 55/05, 71/05-ispravka i 101/07. 
SOYEUN, K. \& TAZIM, J. The co-evolution of rural tourism and sustainable rural development in Hongdong, Korea: complexity, conflict and local response. Journal of Sustainable Tourism, 2015, Vol. 23, N 8-9, p. 1363-1385.

STANKOV, U. Mogucnosti kreiranja odrzivog ruralnog turizma u Backoj. Collection of papers Geographical Institute Jovan Cvijić, 2007, № 57, p. 251-259.

ŠTETIĆ, S.; CVIJANOVIĆ, D. \& ŠIMIČEVIĆ, D. Posebni oblici turizma Dunavskog regiona Srbije. Beograd: Institut za ekonomiku poljoprivrede, 2014.

ŠTETIĆ, S. \& ŠIMIČEVIĆ, D. How to Develope Sustainable Tourism in Rural Destinations in Serbia. Bulletin of the Serbian Geographical Society, 2008, Vol. 88, N 4, p. 19-28.

STOJANOVIĆ, V.; VELOJIĆ, M. \& ŠAKIĆ, R. Strategija održivog turizma u specijalnom rezervatu prirode Gornje Podunavlje. 2012. Disponible en internet: http:/.vojvodinasume.rs/wp-content/ uploads/2012/04/Strategija-razvoja-odrzivog-turizma_SRP-Gornje-Podunavlje.pdf

TAZIM, J. \& TANAS, A. Impacts and Conflicts Surrounding Dracula Park, Romania: The Role of Sustainable Tourism Principle. Journal of Sustainable Tourism, 2005, Vol. 13, № 5, p. 440-455.

WORLD TRAVEL \& TOURISM COUNCIL (WTTC) / ORGANIZACIÓN MUNDIAL DEL COMERCIO (OMC) / Consejo de la Tierra. Agenda 21 for the Travel and Tourism Industry. 1996. Disponsible en internet: http://ethics.unwto.org/sites/all/files/docpdf/ bosniaserbian.pdf 